us into a mode that resulted in the loss of most of a drawing.

\section{Perfect Illustrator}

Aside from a substantial library of clip art pictures and symbols (arrows, fill patterns, etc.), Perfect Illustrator contains only rudimentary drawing tools. Unfortunately, its bare bones aspects do not make it a particularly easy program to operate. For example, a rectangle must be drawn using four lines. Perfect Illustrator regards those lines as separate objects. Thus if it is determined that the rectangle is too small, there is no way to expand it. The lines must be erased and redrawn. A square can be drawn using a Polygon command, but we had difficulty creating squares whose sides were parallel with the edges of the screen or paper and not tipped on one corner. Perfect Illustrator treats the sides of a polygon as separate objects so that here too expansion or contraction of the figure as a whole cannot be done.

This program requires far too much use of its documentation. Too many things are unobvious. Just getting an arrow onto the tip of a straight line requires considerable first time effort.

Perfect Illustrator appears to offer no way to stop a print job. And, if the printer is not connected, the program hangs up, requiring a return to DOS and a reboot.

With all of its flaws, Perfect Illustrator has its virtues. It can make the most of an $81 / 2 \times 11$ sheet by printing in landscape mode in reduced form. Its fonts are clean and attractive, and it is designed so that its drawings can be easily inserted into WordPerfect and Ventura Publisher.

\section{Conclusions}

If all that a user requires is the production of a simple line and box diagram, he or she should use the dedicated organization/flow chart program that fits available hardware. If a wide variety of charts is needed and the quality of output is important, RFFlow is the program we would pick for IBM and compatible computers. We would also select it because of its ease of use. However, the reader is reminded that RFFlow requires the use of Microsoft Windows which can bring the total cost to approximately $\$ 180$.

If more complex graphics must be produced, MacDraft is by far the best choice. Even someone who has never used a Macintosh will find MacDraft a far better drawing tool than comparably priced IBM and compatible programs. We were unable to obtain access to other Macintosh drawing programs, but we believe that if they are available to the user, they should be tried before IBM programs.

If all that is available is an IBM or compatible, Generic CADD is the best drawing program value that we have been able to locate including many shareware programs. However, the prospective user must expect to devote several hours to learning basics before even a simple drawing can be produced. If only single page portrait output is needed and the user does not want to deal with Generic CADD's many irritations, CoDraw is a good choice. It is especially effective for the preparation of transparencies because of its bold if not perfectly formed fonts and the ease with which various fonts can be used on one page.

\section{Notes}

1. Carl Grafton and Anne Permaloff, "Microcomputer Statistical Packages," PS: Political Science and Politics (Winter 1988), $\mathrm{XX}, 1,71-82$.

2. Shareware is distributed free of charge or at a very low price with the idea that someone who finds it useful is morally obligated to register with the manufacturer. Registration fees usually range from $\$ 15-\$ 75$. The registered user typically receives a printed manual, sometimes an improved version of the program, and notification of upgrades.

3. EasyCASE produces charts in accordance with the Yourdon-DeMarco, Gane and Sarson, Ward-Mellor, Hatley-Pirbhai, Yourdon-

Constantine and Chen representations and methodologies for structured analysis and design.

4. For a review of the leading low priced paint programs see Luisa Simone, "Power Painting on a Budget," PC Magazine, December 26, 1989, 241-248.

\title{
The Political Science Oral History Program
}

\author{
Malcolm E. Jewell, Program Director, University of Kentucky
}

The Political Science Oral History Program had its origins in the late 1970 s as an effort to preserve the experiences and perspectives of major figures in the political science profession through interviews conducted by their colleagues. The subjects to be initially interviewed were chosen as a result of a survey of leading political scientists conducted by the APSA. The interviews were recorded and transcribed, and excerpts from some of them appeared in the APSA newsletter on teaching. But no other use was made of the interviews.

The APSA operated the program for the first few years, with financial assistance from Pi Sigma Alpha, the political science honorary. In $1982 \mathrm{Pi}$ Sigma Alpha accepted responsibility for the program and continued to provide some financial support. During the first ten years (1978-87) about twenty interviews were recorded and transcribed, but the pace of interviewing slowed down in the latter years.

In 1987 Pi Sigma Alpha and the
American Political Science Association decided to transfer the program to the University of Kentucky. The purpose of the change was to give the project a stronger professional base and increase the rate of interviews. The University of Kentucky Library has an experienced oral history staff, directed by Terry Birdwhistell, which has assumed the responsibility for compiling transcriptions and maintaining the tapes and transcriptions. Pi Sigma Alpha and the American Political Science 
Association have each provided annual support for the program of $\$ 5,000$, and the University provides support in administering the program.

My major responsibility, as director of the program, is to plan and schedule interviews, with the advice of a committee from the American Political Science Association and Pi Sigma Alpha, chaired by Karl Cerny, and including William Daniels, Robert Huckshorn, A.F.K. Organski, and Elinor Ostrom.

This is a progress report on what has been accomplished since the program was transferred to the University of Kentucky in 1987.

The transcripts of previously completed interviews have been transferred to computer disks, using optical scanning techniques; where necessary, drafts of the earlier interviews have been corrected. Approximately fifteen new interviews with political scientists have been completed and transcribed on a word processor, and a number of others have been scheduled. The tapes and transcripts of these interviews will be made available to interested scholars, under arrangements described later in this report.

\section{Selecting Subjects for Interviews}

The basic purpose of the oral history interviews is to trace the intellectual and institutional growth of the political science profession by recording the career experiences and viewpoints of individuals who have played important roles in its development.

The program started too late to interview the real pioneers in the political science profession, men like Charles Merriam, Leonard White, or Edward Corwin. But it was successful in interviewing a number of the men and a few of the women who played major roles in the development of modern political science. Typically these were persons who received their graduate training in the 1920 s and 1930s and very often served in Washington during the war years, and whose teaching and research careers spanned the period from the end of the war into the 1970s.

In the last few years we have begun to interview members of the next generation, typically those who either had retired or had achieved senior status during the 1980s.

Because of the size and diversity of this group of political scientists, it is more difficult to select a small group of "great men and women" for interviews. Consequently, we have followed a strategy of diversity in selecting subjects. This includes persons who have played significant roles in the major intellectual developments in the discipline and have participated in major research projects in recent decades. We are particularly interested in interviewing those who have been deeply involved in major institutional developments in the profession, such as the APSA and its Review, the Social Science Research Council and its major committees, the ICPSR, and the regional organizations.

The interviews already completed with political scientists include half a dozen women. We are working with the APSA Committee on the Status of Women to identify a number of other senior female political scientists who ought to be interviewed in the near future.

\section{Interviews with Black Political Scientists}

The APSA has received a $\$ 25,000$ grant from the Ford Foundation to expand the Political Science Oral History Program by carrying out interviews with approximately fifteen senior black political scientists. The purpose is to record the contribution of blacks to the development of the profession and to better understand the factors that both helped and hindered their participation. It is important to record the viewpoints of black political scientists on the intellectual issues facing political science and their opinions about the contribution that political science can make toward resolving issues of particular concern to blacks.

We have established an advisory committee, consisting of Twiley Barker, William Daniels, Jewel Prestage, Michael Preston, Mitchell Rice, and Maurice Woodard, which met during the 1989 APSA meeting and developed a list of black political scientists with whom interviews will be sought. Several members of the committee will also conduct a number of the interviews. The first of these interviews are already under way.

These interviews will be transcribed at the University of Kentucky and made available to scholars as part of the Oral History Program. In addition, a volume will be published on the role of blacks in the development of the political science profession, consisting of edited excerpts from these interviews and several others previously conducted.

\section{Publication of Oral Histories}

Work is nearing completion on a volume of edited excerpts from interviews with fifteen political scientists, including some who were interviewed a decade ago and some of those interviewed more recently. The book has been edited by Michael Baer, Lee Sigelman, and Malcolm Jewell, and it has been submitted to a university press.

\section{Scholarly Use of the Oral Histories}

The original tapes and the completed transcripts of interviews in the Political Science Oral History project are maintained at the University of Kentucky. Scholars who want more information about using these materials should write: Jeffrey Suchanek, Special Collections, University of Kentucky Library, Lexington, KY 40506-0039.

Copies of the transcripts will also be made a part of the Pi Sigma Alpha Archive at Georgetown University Library in Washington, D.C. Interested scholars will be able to make arrangements to read the transcripts at the Library.

The following is a list of the interviews for which completed transcripts are now available at the University of Kentucky Library (and will soon be at Georgetown University): Gabriel Almond, Taylor Cole, Manning J. Dauer, James W. Fesler, Ernest Griffith, E. Pendleton Herring, Charles Hyneman, Harvey C. Mansfield, Don K. Price, C. Herman Pritchett, Austin Ranney, Emmett S. Redford, David B. Truman, and Belle Zeller.

Some of the interviews that have been completed are being tran- 
scribed, or the transcriptions are being corrected, at the present time. The following is a list of these interviews, which should be available by January, 1991: Vincent R. Browne, James M. Burns, Gwendolyn Carter,
Robert A. Dahl, David Easton, Leon Epstein, Heinz Eulau, Marian Irish, Robert Martin, Warren Miller, Louise Overaker, William Riker, John Turner, Vernon Van Dyke, and John Wahlke.

\title{
NEH Projects Dealing with Women and Politics Themes*
}

\author{
Kenneth Kolson, Deputy to the Director, Division of \\ Education Programs, National Endowment for the Humanities
}

I.

\section{Overview of the NEH**}

In order to "promote progress and scholarship in the humanities and the arts in the United States," Congress passed the National :oundation on the Arts and Humanities Act of 1965. This act established the National Endowment for the Humanities as an independent grantmaking agency of the federal government to support research, education, and public programs in the humanities. Grants are made through five divisions-Education Programs, Fellowships and Seminars, General Programs, Research Programs, and State Programs, and two offices, the Office of Challenge Grants and the Office of Preservation.

The staff of these divisions and offices guide applications through a peer review process to recommend projects for funding. The final responsibility for awards rests by law with the Chairman of the Endowment, who is appointed for a fouryear term by the President of the United States, with the advice and consent of the Senate. The Chairman is advised by the National Council on the Humanities, twenty-six distinguished private citizens who are also nominated by the President and confirmed by the Senate.

\section{The Humanities}

In the act that established the National Endowment for the Humanities, the term humanities includes, but is not limited to, the study of the following disciplines: history; philosophy; languages; linguistics; literature; archaeology; jurisprudence; the history, theory, and criticism of the arts; ethics; comparative religion; and those aspects of the social sciences that employ historical or philosophical approaches.

\section{What the Endowment Supports}

The National Endowment for the Humanities supports exemplary work to advance and disseminate knowledge in all the disciplines of the humanities. Endowment support is intended to complement and assist private and local efforts and to serve as a catalyst to increase nonfederal support for projects of high quality.

Although the activities funded by the Endowment vary greatly in cost, in the numbers of people involved, and in their specific intents and benefits, they all have in common two requirements for funding: significance to learning in the humanities and excellence in conception.

\section{How Applications Are Evaluated}

Generally, each application submitted to Endowment programs is assessed by knowledgeable persons outside the Endowment who are asked for their judgments about the quality of the proposed project. Nearly 1,000 scholars and professionals in the humanities serve on approximately 150 panels throughout the course of a year. The judgment of panelists is often supplemented by individual reviews solicited from specialists who have extensive knowledge of the specific subject area dealt with in the application. The Endowment receives approximately 8,000
When additional interviews have been completed and transcribed, information about their availability will be released, approximately once a year, in $P S$. applications each year, of which about 2,800 are funded. Our annual budget is in the neighborhood of $\$ 150$ million, of which only about $15 \%$ is spent on administration.

\section{Special Initiatives}

The Foundations of American Society. Within its existing programs, the Endowment has encouraged study, research, and discussion about the history, culture, and principles of the foundation period, an emphasis that began with the NEH initiative on the bicentennial of the U.S. Constitution. Proposals may deal directly with the events and achievements of the founding period, including the ratification of the Constitution, the establishment of the federal government, and the works of philosophy, politics, literature, and art that were produced during the founding period. They may also treat later events, achievements, and works that have resulted or developed from the founding period or that reflect or respond to its concerns and principles.

The Columbian Quincentenary. As part of the international observance of the 500th anniversary of Christopher Columbus's voyage of discovery to the New World, NEH invites proposals for original scholarship on related topics and for the dissemination of both new and existing scholarship. Topics may include the expansion of European civilization through the efforts of the Spanish and Portuguese crowns and the establishment of new societies and new forms of cultural expression through encounters among native American, European, and African 